\title{
Preventing insulin dependent diabetes mellitus
}

\author{
Promising strategies, but formidable hurdles still to clear
}

The ultimate goal for those who care for people with insulin dependent diabetes is prevention. This seemed a futile quest until the 1970s when the aetiology of the condition began to be unravelled. Insulin dependent diabetes mellitus was shown to be an autoimmune disorder with a genetic basis, strongly associated with the class II alleles DR3 and DR4. This led to a series of studies of immunosuppression, mainly using cyclosporin, ${ }^{12}$ but also azathiaprine ${ }^{3}$ and steroids, in patients newly presenting with insulin dependent diabetes mellitus.

Cyclosporin proved relatively effective in delaying insulin dependence and inducing prolonged remissions. It was particularly useful within four weeks of diagnosis and in patients with moderate symptoms and no weight loss. ${ }^{4}$ The lack of total success is not surprising given that more than $90 \%$ of $\beta$ cells have been destroyed by the time of diagnosis. Intensive insulin treatment may also prolong remissions, presumably through decreasing "glucotoxicity."

But there are several problems with these approaches. Firstly, they come too late in the course of the disease, and any intervention would probably have to be life long to maintain remission. Secondly, many of the agents used are non-specific and have appreciable side effects. This is particularly true of cyclosporin, which ironically is toxic to $\beta$ cells. Ethically, therefore, routine broad spectrum immunosuppression is unacceptable when used for a disease where life expectancy is considerable with conventional insulin treatment, albeit with the risk of developing complications of diabetes. Interventions should therefore be non-toxic and made at an earlier stage to be acceptable and effective- that is, before most $\beta$ cells have been destroyed.

The Barts-Windsor study showed that non-diabetic siblings of patients with insulin dependent diabetes mellitus developed islet cell antibodies many years before the development of clinical diabetes. ${ }^{5}$ With high antibody titres the risk of developing diabetes was about $50 \%$. More recently, a series of other autoantibodies have been discovered, including insulin autoantibodies, antibodies to glutamic acid decarboxylase, and islet cell $69 \mathrm{kDa}$ antibodies. ${ }^{67}$ The presence of two or more of these antibodies increases the risk of developing insulin dependent diabetes mellitus to up to $90 \%$ - a level that makes intervention worth while. In addition, the measurement of first phase insulin secretion (the pulse of insulin that is secreted in the first few minutes after a glucose stimulus) gives a sensitive marker and predictor of the rate of progression to diabetes.

This seems an ideal setting in which to test preventive agents. Many have been suggested, several of which were discussed at a recent meeting. ${ }^{8}$ Dietary intervention is the most appealing intervention (because it is simple and involves no drugs) but the least likely to succeed (because people would have discovered it by now given its simplicity). It is based on the assumption that nutritional factors, such as nitrosamines or proteins, trigger the diabetogenic process. The most likely dietary factor is bovine albumin because breast feeding has been shown to protect against the development of insulin dependent diabetes mellitus and diabetic children have antibodies to bovine serum albumin. Interestingly, bovine serum albumin contains a 17 amino acid sequence that cross reacts with a protein on the surface of $\beta$ cells. A 10 year, 3000 family study is planned in Scandinavia in which the test group will have no cows' milk for the first nine months of life. ${ }^{9}$

Skyler and Marks recently listed a further 29 possible interventions. ${ }^{10}$ These were divided into generalised immunosuppressants, anti-inflammatory agents, non-specific immunomodulators, semi-specific immunotherapy, free radical scavengers, and $\beta$ cell "rest" agents (insulin). Several more were discussed at the recent meeting of the European Association for the Study of Diabetes, including aminoguanidine, vitamin $\mathrm{D}_{3}$, antioxidants, tumour necrosis factor, and Freund's adjuvant.

Only a few of these are being used at present. Potential toxicity has halted studies with azathioprine and cyclosporin, although promising results were obtained. The current main candidates are subcutaneous insulin, oral insulin, glutamic acid decarboxylase, and nicotinamide. A pilot study from the Joslin Clinic in Boston has shown preservation of $\beta$ cell function and apparent prevention of diabetes with daily subcutaneous insulin and intensive intravenous insulin every 9 months in a group of subjects with predicted development of diabetes within three years. ${ }^{11}$ Six of seven controls developed diabetes within three years compared with none of the five treated subjects. A large multicentre trial is now planned. Oral antigen treatment with insulin and glutamic acid decarboxylasae also looks interesting and has been successful in animal models. This treatment is based on the finding that the ingestion of $T$ lymphocyte dependent antigens can establish immunological tolerance. Results of human studies will be awaited with interest.

Currently, however, most attention is focused on nicotinamide. A series of studies from New Zealand, largely uncontrolled and unconfirmed elsewhere, strongly suggests 
that nicotinamide induces remissions in patients with newly diagnosed insulin dependent diabetes and delays the onset of diabetes in antibody positive non-diabetic children. ${ }^{12}{ }^{13}$ It is suggested that it works in the $\beta$ cell by two mechanisms: increasing the nicotinamide adenine dinucleotide pool required for poly(ADP-ribosyl) action and inhibiting the action of the molecular enzyme poly(ADP-ribose) polymerase. ${ }^{14}$ These processes are implicated in DNA repair, which may be important in early insulin dependent diabetes mellitus. ${ }^{15}$ Nicotinamide may also increase the number of mutations, although only at a high dose.

A carefully designed multicentre trial has been set up with the well chosen acronym of ENDIT (European Nicotinamide Diabetes Intervention Trial) and coordinated by Edwin Gale at St Bartholomew's Hospital, London. About 22000 first degree relatives of patients with insulin dependent diabetes mellitus will be screened, yielding about 500 people with islet cell antibodies who will be treated with nicotinamide or placebo for five years. Other promising avenues include the use of highly specific monoclonal antibodies, but these are still well removed from large scale intervention studies.

The prospects of intervention in "prediabetes" are thus exciting, but substantial problems exist. Firstly, nearly all studies to date have focused on first degree relatives. Familial insulin dependent diabetes mellitus, however, provides the minority of cases- $85 \%$ to $90 \%$ of cases are sporadic. Population screening will be needed to detect all cases of "prediabetes" and this will be complex, expensive, and, certainly in Britain, unfavourably received by our parsimonious NHS. It will also be necessary to establish that sporadic cases, all ethnic groups, and patients with late onset insulin dependent diabetes mellitus, respond in the same way as first degree relatives.

Secondly, people with prediabetes are healthy except that they will develop diabetes at some indefinite time later. Any intervention will therefore have to be virtually harmless. This is not true for many of the strategies proposed to date. Even subcutaneous insulin in small doses is not totally harmless.
Although nicotinamide is a "natural" substance, the amounts to be used are much greater than the recommended daily allowance for nutritional purposes. Careful studies to date, however, have not revealed any toxicity in humans.

The prospects of preventing diabetes are considerably more hopeful than a decade ago, but the problems remain formidable-and another decade may well pass before we have an acceptable preventive treatment and can reach all those who need it.

Department of Medicine,

K G M M ALBERTI

The Medical School,

Newcastle upon Tyne NE2 4HH

1 Stiller CR, Dupre J, Gent M, Jenner MR, Keown PA, Laupacis A, et al. Effects of cyclosporine immunosuppression in insulin-dependent diabetes mellitus of recent onset. Science 1984;223: $1362-7$.

2 The Canadian European Randomized Control Trial Group. Cyclosporin-induced remission of IDDM after early intervention: association of 1 year of cyclosporin treatment with enhanced insulin secretion. Diabetes 1988:37:1574-82.

3 Harrison LC, Colman PG, Dean B, Baxter R, Martin FIR. Increase in remission rate in newly diagnosed type 1 diabetic subjects treated with azothioprine. Diabetes 1985;34:1306-8.

4 Bougneres PF, Carel JC, Castano L, Boitard C, Gardin JP, Landais P, et al. Factors associated with early remission of type 1 diabetes in children treated with cyclosporine. $N$ Engl $7 \mathrm{Med}$ 1988:318:663-70.

5 Tarn AC, Dean BM, Schwarz G, Thomas JM, Ingram D, Bottazzo GF, et al. Predicting insulindependent diabetes. Lancet 1988;i:845-50.

6 Baekkeskov S, Aanstoot H, Christgau S, Reetz A, Solimeena MS, Cascalho M, et al. Identification of the $64 \mathrm{~K}$ autoantigen in insulin dependent diabetes as the GABA-synthesizing enzyme glutamic acid decarboxylase. Nature 1990;347:151-6.

7 Pietropaolo M, Castano L, Babu S, Buelow R, Kuo Y-LS, Martin S, et al. Islet cell autoantigen $69 \mathrm{kDa}$ (ICA69): molecular cloning and characterization of a novel diabetes associated autoantigen. 7 Clin Invest 1993;92:359-71.

8 Laron Z, Karp M, eds. Prediabetes-are we ready to intervene? Paediatric and Adolescent Endocrinology. Basel: Karger, 1993;23.

9 Akerblom HK, Dosch H-M, Robinson BH, Knip M, Karjalainen J, Savilahti E, et al. Is dietary intervention for the prevention of insulin-dependent diabetes mellitus feasible? In: Laron $Z$, Karp M, eds. Paediatric and Adolescent Endocrinology. Basel: Karger, 1993;23:97-104.

10 Skyler JS, Marks JB. Immune intervention in type 1 diabetes mellitus. Diabetes Reviews 1993; 15-42.

11 Keller RJ, Eisenbarth GS, Jackson RA. Insulin prophylaxis in individuals at high risk of type diabetes. Lancet 1993;341:927-8.

12 Elliott RB, Pilcher CC, McGregor M, Ashbey J, Nicolls F, Ferguson D. Prevention of diabetes in large cohort of school children. In: Laron Z, Karp M, eds. Prediabetes-are we ready to intervene? Paediatric and Adolescent Endocrinology. Basel: Karger, 1993;23:119-25.

13 Elliott RB, Chase HP. Prevention or delay of type 1 (insulin-dependent) diabetes mellitus in children using nicatinamide. Diabetologia 1991;34:362-5.

14 Pociot F, Reimers II, Anderson HU. Nicotinamide--biological actions and therapeutic potential in diabetes prevention. Diabetologia 1993;36:574-6.

15 Eizirik DL, Sandler S, Palmer JP. Repair of pancreatic $\beta$ cells. A relevant phenomenon in early IDDM? Diabetes 1993;42:1383-91.

\section{Efficient purchasing}

\section{The current efficiency index needs changing or scrapping}

With all the current talk about efficiency in the NHS it may surprise doctors that a measure called the efficiency index is being used to assess purchasers' performance. Health service managers and researchers are concerned about the index's construction and use. ${ }^{1}$ Although the Department of Health is about to modify the way that the index is calculated, these changes may fail to address both the fundamental flaws in the way that efficiency is measured and how the pursuit of increases in the index is distorting the behaviour of purchasers and providers.

Currently, the index is calculated by dividing year on year changes in purchased health care activity by changes in districts' financial allocations. The measures of activity used are finished consultant episodes for ordinary admission and day cases; outpatient, accident and emergency, and day care attendances; community contracts; and ambulance journeys. These are weighted according to their share of health care spending so that, for example, a consultant episode is given more weight than an ambulance journey. ${ }^{2}$ The main reason for introducing the index is to reassure the Treasury that the NHS is spending taxpayers' money efficiently. Every year, the NHS Management Executive requires health authorities to achieve increases in the index, and recent planning guidelines indicate that districts will be expected to achieve an increase of $2 \%$ next year. ${ }^{3}$ This is on top of the $2 \%$ increase required this year.

Both the financial and the activity components of the index are, however, flawed. Comparison of the amount of money spent on direct patient care is complicated by differences in providers' capital charges and variations in districts' weighted capitation formulas. ${ }^{1}$ Differences in the way that providers define episodes of care and variations in patterns of treatment - especially for patients with chronic, terminal, or psychiatric illnesses-make the use of episodes almost meaningless. ${ }^{4-6}$ This problem is reduced but not eliminated for conditions treated by a single intervention, such as elective surgery, but these represent a small proportion of total health service activity.

But even if the difficulties of measuring finance and activity could be overcome, the most fundamental problem-the lack of a consistently meaningful relation between the two-would remain untouched. Using crude activity (the process of health 